\title{
A UFNAHMEBEDINGUNGEN
}

1. Es werden nur Arbeiten angenommen, die nicht an anderer Stelle mit demselben Inhalt veröffentlicht oder zur Veröffentlichung angeboten werden. Der Autor verpflichtet sich nach Annahme, die Arbeit an keiner anderen Stelle zu veröffentlichen.

2. Die Arbeit muß wissenschaftlich wertvoll sein. Bestätigungen bekannter Tatsachen, Versuche und Beobachtungen ohne positives Ergebnis werden, wenn überhaupt, nur in kürzester Form aufgenommen. Nicht aufgenommen werden Arbeiten referierenden Charakters, Polemiken und rein spekulative Arbeiten, falls sie nicht ganz wesentliche neue Gesichtspunkte enthalten.

3. Kurzmitteilungen für experimentelle Ergebnisse werden bei der Drucklegung zeitlich bevorzugt. Für ihren Inhalt ist ausschließlich der Autor verantwortlich.

4. Die Arbeiten müssen kurz und klar geschrieben und gegliedert sein. Problematik (Einleitung), Methodik, Befunde und Diskussion, evtl. Schlußfolgerungen sollen deutlich in Erscheinung treten. Der Arbeit soll ein Kurzreferat der wesentlichsten Ergebnisse vorausgestellt werden. Neben einer anderssprachigen erscheint auf jeden Fall eine deutsche Zusammenfassung. Die Arbeiten werden in folgenden Sprachen angenommen: Deutsch, Russisch, Englisch und Französisch.

5. Die Arbeiten werden im Sofortumbruch gesetzt; größere Korrekturen in Form von Streichungen bzw. Zusätzen sind daher in der Umbruchkorrektur nicht mehr möglich.

6. Genaue Hinweise zur Manuskriptgestaltung sind von der Redaktion der Zeitschrift anzufordern und sind unbedingt einzuhalten.

7. Manuskripte sind an die Herausgeber zu senden oder direkt an die Redaktion der Acta biologica et medica germanica, 1115 Berlin-Buch, Lindenberger Weg 70.

8. Von jeder Originalarbeit werden kostenlos 80 Sonderdrucke geliefert. Darüber hinaus können bis zu 100 Sonderdrucke gegen Berechnung bezogen werden. 


\title{
ACTA BIOLOGICA ET MEDICA GERMANICA
}

\author{
Herausgeber:
}

R. Baumann - H.Dutz.A.Graffi - H. Gummel F. Jung - L.-H. Kettler

S. M. Rapoport

Band 16

1966

Heft 6

Acta biol. med. german., Band 16, Seite 575- 585 (1966)

Aus dem Lehrstuhl Chemie (Leiter: Doz. Dr. rer. nat. A. BARTH) des Instituts für Naturwissenschaften (Direktor: Doz. Dr. habil. C. Sснẅ̈R) und dem chemischen Zentrallabor (Leiter: Doz. Dr. rer. nat. I. PiLCH) der Hochschule für Landwirtschaft Bernburg/Saale

\section{Über Aminosäure-4-(phenylazo)-phenyl-Derivate ${ }^{1}$}

XI. L-Alanin-4-(phenylazo)-phenylamid als Substrat für die kolorimetrische Aktivitätsermittlung von Aminosäurearylamidasen im Serum

A. Barth, K.-H. Hoffmann und I. Pilch

(Eingegangen am 25.11. 1965) ${ }^{2}$

\section{Zusammenfassung}

Es wird eine Methode zur Bestimmung der Aminosäurearylamidaseaktivität im Serum unter Verwendung des neuen Substrates L-Alanin-4-(phenylazo)-phenylamid beschrieben, aus dem bei der enzymatisch katalysierten Hydrolyse das farbige Phenylazophenylamin freigesetzt wird, dessen Konzentration kolorimetrisch bei $500 \mathrm{~nm}$ ermittelt werden kann. Für die somit mögliche Aktivitätsanalyse wurden die optimalen Reaktionsbedingungen ermittelt. Das Verfahren eignet sich für die routinemäßige Aktivitätsbestimmung der Aminosäurearylamidase und hat auf Grund sehr einfacher Ausführung und größerer Empfindlichkeit entscheidende Vorteile gegenüber der Bestimmung mit L-Leuzin- $\beta$-naphthylamid als Substrat.

Das zur Zeit für die Bestimmung von Aminosäurearylamidasen am meisten angewendete Substrat ist zweifellos L-Leuzin- $\beta$-naphthylamid, das für kolorimetrische Messungen seit GREEN et al. [1], insbesondere auch in der Modifikation von WEBER [2], recht gut geeignet ist. Abgesehen vom Wert der Spezifität bisher verwendeter Substrate dürften jedoch für allgemeine Routineanalysen künftig vorwiegend Substrate vom Typ der Aminosäure-pnitroanilide [3], [4], die selbst nur schwach gefärbt sind und deren proteolytisch freigesetztes, farbiges Amin nach der Inkubation sofort kolorimetriert werden kann, den Vorzug genießen [5].

${ }^{1}$ IV. Mitteilung über Aminosäure-PAP-amide. - III. Mitteilung: A. BARTH und P. Schwenk; Acta chim. Acad. Sci. hung. (im Druck)

2 Nach Revision am 11. 1. 1965. 


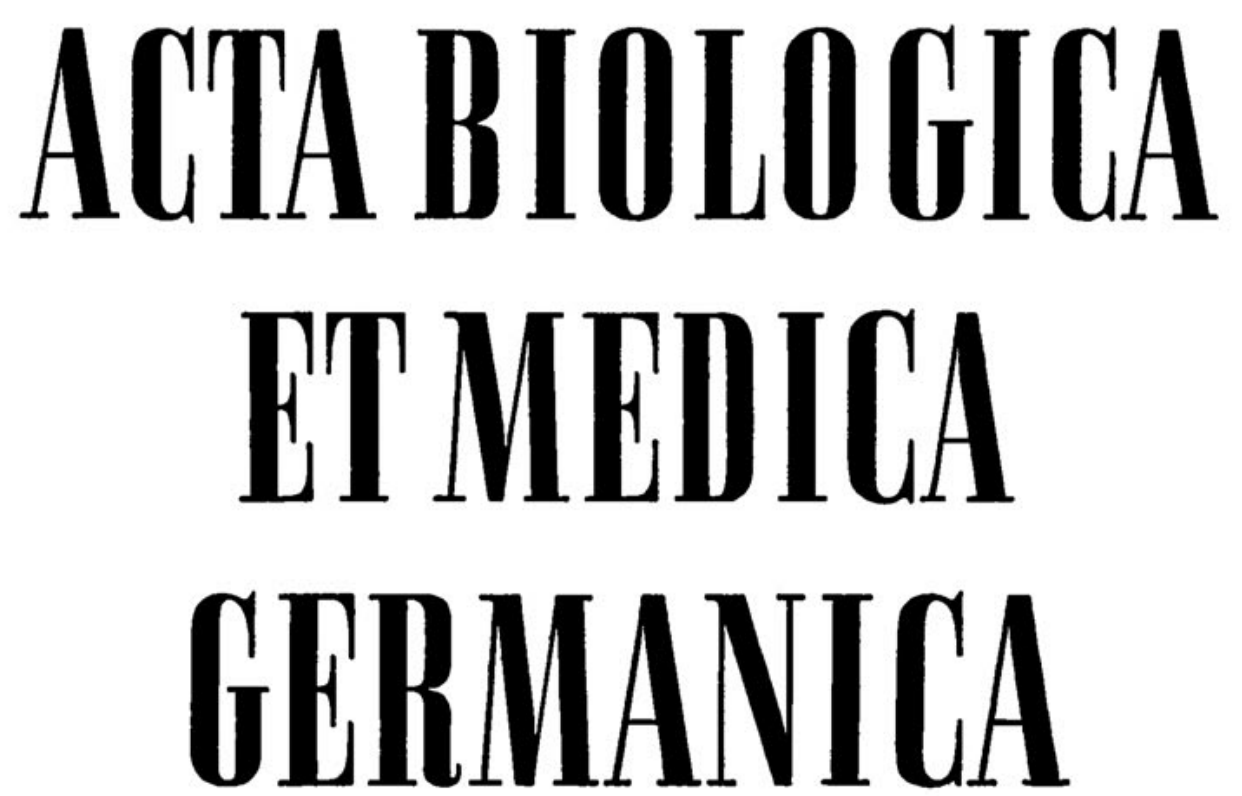

HERAUSGEBER:

R. BAUMANN, H. DUTZ, A. GRAFFI, H. GUMMEL, F. JUNG L.-H. KETTLER, S. M. RAPOPORT

UNTER MITARBEIT VON:

W. BEIER, H. DRISCHEL, H. FRUNDER, M. GERSCH, E. GOETZE, H. HANSON, F. HAUSCHILD, G. HOLLE, F. MACH, H. MATTHIES, G. MOHNIKE†, O. PROKOP, K. SCHUBERT, F. SCHWARZ,

G. STERBA, A. WOLLENBERGER

SCHRIFTLEITUNG:

W. SCHELER, H. BIELKA

Band 16

1966

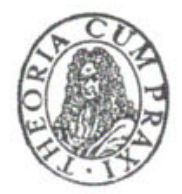

AKADEMIE-VERLAG - BERLIN 


\section{央}

Herausgeber und verantwortlich für den Inhalt: R. Baumann, H. Dutz, A. Graffi, H. Gummel, F. Jung, Prof. Dr. L.-H. Kettler, S.-M. Rapoport. Schriftleitung: Prof. Dr. Werner Scheler und Dr. habil. Heinz Bielka, 1115 Berlin-Buch, Lindenberger Weg 70. Fernruf: 5698 51. App. 222. Verlag: Akademie-Verlag GmbH, 108 Berlin, Leipziger Straße 3-4, (Fernruf: 220441) Telex-Nr. 011773, Postscheckkonto Berlin 35021. Bestell- und Verlags-Nr. dieses Bandes 1053/XVI. Die Zeitschrift erscheint monatlich. Bezugspreis: Einzelheft MDN 14,-, Doppelheft MDN 28,-. Veröffentlicht unter der Lizenznummer 1318 des Presseamtes beim Vorsitzenden des Ministerrates der Deutschen Demokratischen Republik. Gesamtherstellung: VEB Druckerei „Thomas Müntzer", 582 Bad Langensalza. - Alle Rechte vorbehalten, insbesondere die der Übersetzung. Kein Teil dieser Zeitschrift darf in irgendeiner Form - durch Photokopie, Mikrofilm oder irgendein anderes Verfahren - ohne schriftliche Genehmigung des Verlages reproduziert werden. 